Full Length Article

\title{
From desire to development? A multi-sample, idiographic examination of volitional personality change
}

\author{
Erica Baranski ${ }^{\text {a,*}}$, Jacob Gray ${ }^{b}$, Patrick Morse ${ }^{c}$, William Dunlop ${ }^{\mathrm{d}}$ \\ ${ }^{a}$ The University of Arizona, United States \\ ${ }^{\mathrm{b}}$ Dynamic Measurement Group, United States \\ ${ }^{\mathrm{c}}$ Belmont University, United States \\ ${ }^{\mathrm{d}}$ The University of California, Riverside, United States
}

\section{A R T I C L E I N F O}

\section{Article history:}

Received 12 April 2019

Revised 16 December 2019

Accepted 17 December 2019

Available online 26 December 2019

\section{Keywords:}

Volitional personality change

Idiographic-nomothetic

Personality development

\begin{abstract}
A B S T R A C T
Using an idiographic-nomothetic methodology, we assessed individuals' ability to change their personality traits without therapeutic or experimental involvement. Participants from internet and college populations completed trait measures and reported current personality change desires. Self-reported traits as well as perceptions of trait change were collected after 1-year (Internet) and 6-months (College). In large part, volitional personality change desires did not predict actual change. When desires did predict change, (a) desired increases in Extraversion, Agreeableness and Conscientiousness corresponded with decreases in corresponding traits, (b) participants perceived more change than actually occurred, and (c) decreases in Emotional Stability predicted perceptions of personality change. Results illustrate the difficulty in purposefully changing one's traits when left to one's own devices.
\end{abstract}

(c) 2019 Elsevier Inc. All rights reserved.

\section{Introduction}

Moments inciting personality change abound: the reserved college freshman eager to make friends, the young adult attempting to transition to a demanding full-time job and the new parent practicing patience. While it may or may not be obvious to these individuals, there are several mechanisms and processes that have been associated with changes in personality traits, including therapeutic coaching (Boyatzis \& Akrivou, 2006; Boyatzis, 2006), psychotherapy (Roberts et al., 2017), and one's volitional efforts to change (Allemand and Flückiger, 2017; Baranski, Morse, \& Dunlop, 2017; Hudson \& Fraley, 2015; Robinson et al., 2015; Quintus, Egloff, \& Wrzus, 2017).

Of the aforementioned processes, clinical and counseling practices have garnered the most research attention. Indeed, a critical assumption in the field of clinical psychology is the potential for agentic self-improvement. While clinical psychologists have long recognized psychotherapy as a successful route towards personality change, until recently, little research in personality psychology has investigated one's ability to purposefully, or volitionally, change their personalities. When personality psychologists have examined volitional personality change, their investigations have produced mixed results (Hudson \& Fraley, 2016; Robinson et al., 2015). In

\footnotetext{
* Corresponding author.

E-mail address: ericanbaranski@gmail.com (E. Baranski).
}

the current study, we draw from two demographically distinct, non-clinical samples, to further explore this volitional personality change process. To do so, we utilized an open-ended, idiographic-nomothetic measurement approach assessing individuals' motivations for, and perceptions of, personality change. Said motivations and perceptions were then explored in relation to actual personality change.

\subsection{Therapeutic coaching and personality change studies}

Therapeutic coaching and previous personality change studies offer a solid foundation for discussing the individual's ability to change their own personality traits and the boundaries for which effortful personality change is possible. It might be the case, for instance, that only when individuals are coached through the personality change process are they able to successful change. Importantly, these methods also offer a theoretical framework for the volitional personality change process.

\subsubsection{Therapeutic coaching}

Clinical psychologists have long noted the tendency for individuals to (1) recognize a gap between their ideal and actual selves and (2) seek therapeutic coaching to close this gap (Boyatzis \& Akrivou, 2006; Boyatzis, 2006; Frisch, 2013; Martin, Oades, \& Caputi, 2012, 2014; Spence \& Grant, 2005; Young, Valach, \& Domene, 2005). As such, clinicians have practiced personality 
change coaching as a means to incite long-term personality change in their patients (Martin et al., 2012; McCredie, 2013; Spence \& Grant, 2005). In personality change coaching, clinicians act as a moderator to facilitate concrete behavioral change meant to ultimately influence personality traits (e.g., asserting oneself in a meeting; Boyatzis, 2006; Boyatzis \& McKee, 2006; Martin, Oades, \& Caputi, 2012).

While there is clear evidence that therapeutic coaching is successful in inciting actual change, individuals seeking therapeutic involvement for change may be more apt for change when compared to non-clinical populations, due to the intensity of their personality change desire, the constant involvement from a psychological professional, or a combination of these two factors (or other, additional factors not recognized here).

\subsubsection{Volitional personality change}

Over the last several years, personality psychologists have begun to investigate individuals' active approach towards personality change as a mechanism for development across the lifespan. These endeavors have broadened understanding of the personality development process from the onset of personality change goals (Baranski et al., 2017; Hudson \& Roberts, 2014; Miller, Baranski, Dunlop, \& Ozer, 2019; Robinson et al., 2015; Quintus et al., 2017), to the strategies used to enact said goals (Baranski et al., 2017), to the changes in traits themselves (e.g., Hudson \& Fraley, 2015).

To test the extent to which personality change goals predict actual personality change, Hudson and Fraley (2015, Study 2) tracked college students' desires to change particular traits over the course of a 16-week semester. This was done via the Change Big Five Inventory ( $\mathrm{CBFI}$ ), which asks participants to rate the extent to which they wish to increase or decrease levels of each item of the Big Five Inventory (BFI; e.g., outgoing, sociable; compassionate, soft hearted; see John, Naumann, \& Soto, 2008). Participants in this study were randomly assigned to receive, or not receive, a goalsetting intervention. Those assigned to the intervention condition were first asked to describe three specific goals they intended to use to work towards their desired personality change goal. Each subsequent week, they completed self-report measure of personality traits, were reminded of their personality change goals, asked to rate how successful they had been at accomplishing them, and asked to create a new list of specific goals (with the ability to reuse goals from previous weeks). The authors observed that participants assigned to the intervention condition experienced increases in Extraversion and Emotional Stability when they reported desires to change these traits to a greater degree than those in the control condition with similar personality change desires.

In a similar study, Robinson, Noftle, Guo, Asadi, and Zhang (2015) determined whether the presence of a change goal as well as the specificity of the corresponding plan predicted actual change over a 12-month period. Recent college graduates from the UK, Iran and China completed a Likert-type, FFM-based personality change goal questionnaire (distinct from the $\mathrm{cBFI}$ with respect to the Likert-type scale used, as participants rated their change goals on a 3-point scale as opposed to a 7-point scale), the Big Five Inventory, and a series of open-ended questions assessing their specific plan to change their personality. Unlike Hudson and Fraley's investigation, however, Robinson and colleagues did not follow-up with participants over the course of the study, relying instead on two assessments over a 12-month study period. Also, distinct from Hudson and Fraley, they found that goals to increase levels of Emotional Stability and Conscientiousness actually predicted reductions in these traits over the 12-month term, meaning that those possessing the strongest motivation to increase in Emotional Stability/Conscientiousness exhibited greater declines in these constructs. Robinson and colleagues interpreted these results as bi-products of individuals low in Emotional Stability and Conscientiousness having inherit difficulty accomplishing personality change goals.

While this emerging body of research has made great strides in increasing understanding of the volitional personality change process, definitive conclusions have yet to be reached regarding the nature of the relation between volitional and actual personality change. It may be helpful, therefore, to adopt an assessment strategy distinct from the Likert-type change-based inventories used by Hudson and Fraley (2015) and Robson and colleagues (2015). In particular, an open-ended assessment format also provides the opportunity to assess the ways in which individuals conceptualize their personality change throughout the entire volitional personality change process.

Speaking to the above point, Baranski et al. (2017) have developed an open-ended, narrative-based method for assessing participants' conceptions of their personality change desires. In this measure, individuals are prompted to indicate whether they possess the desire to change an aspect of their personalities. If participants indicate such a desire, they are then asked to describe, in an open-ended manner, the aspect of their personalities they wish to change. Responses are then quantified using 10 non-mutually exclusive, binary categories (i.e., presence/absence) capturing increases and decreases in each dimension of the FFM (i.e., Extraversion, Conscientiousness, Agreeableness, Openness and Emotional Stability). Baranski et al. (2017) noted that participants typically conveyed desires to increase in Extraversion, Agreeableness, Conscientiousness or Emotional Stability in their openended responses - a pattern in line with individual's tendency toward a "functional maturity" (Hogan \& Roberts, 2004). Conversely, less than $10 \%$ of participants' responses were classified as relevant to desires to increases or decrease in Openness to Experience. This provides indication of the way lay persons conceptualize their personalities, and desired change, when outside the context of a formal personality inventory.

\subsection{Idiographic-nomothetic approach to assessing volitional personality change}

The idiographic-nomothetic approach to studying individual differences first collects participants' responses to open-ended responses (e.g., "Describe a life high point"), and then uses quantitative coding methods to quantify psychological relevant aspects of their responses (e.g., positive/negative emotional tone). Thus, this method enables researchers to capture rich, qualitative data about individuals' lives, while applying a systematic, quantitative analytic strategy to the data.

This method may be particularly useful when studying volitional personality change for three reasons. First, it introduces less risk of demand characteristics. For example, participants' ratings to change a series of personality characteristics may be an artifact of the social desirability of goals to improve a particular characteristic. A Likert-type personality change inventory may therefore overestimate the frequency of goals to change a particular trait. Moreover, if both current levels of personality and personality change goals are measured via Likert-type scales, there is an increased risk of common method variance (Biderman, Nguyen, Cunningham, \& Ghorbani, 2011).

Second, asking participants to report their personality change desires in an open-ended format enables them to express a desire that is particularly salient to them. The impact ideographicnomothetic methodology has on response salience and importance has been investigated in the fields of market research (Olson \& Muderrisoglu, 1979), public opinion (Geer, 1991) and patient satisfaction after receiving anesthesia (Bauer, Böhrer, Aichele, Bach, \& Martin, 2001). Across these fields, researchers use the open- 
ended response method to incite participants to report the product, political opinion or impression of their romantic relationship that is particularly important to them, and not one that is influenced by the limited content of a self-report questionnaire.

Finally, an ideographic-nomothetic approach may be a more ecologically valid assessment of volitional personality change goals. Accomplishing personality change goals may be a somewhat tenuous endeavor in the face of other goals one is working towards (e.g., getting a promotion, losing weight; Kaiser \& Ozer, 1997). The most salient among an individual's personality change goals may stand up against other personal goals. Indeed, a recent study demonstrated that when individuals are asked to list their topten goals, the majority include at least one goal to change an aspect of their personality (Miller et al., 2019). Using a combination of idiographic (open-ended) and nomothetic (systematic, quantitative coding) methods would therefore enable researchers to capture change desires that are particularly important to individuals, and thus those that they may spend more time and concerted effort in achieving.

\subsection{The current project}

Both clinical and experimental domains of psychology provide evidence that, with therapeutic coaching, or experimenter involvement, individuals can accomplish their personality change goals. Little is known, however, of individuals' ability to change themselves in the absence of an intervening source (for a notable exception, see Robinson et al., 2015). Moreover, few previous investigations have sought to understand how individuals conceptualize their own personality change outside the context of prespecified Likert-type scales. Moreover, investigating volitional personality change perceptions may yield insight in to the psychological conditions necessary to successfully change personality.

The current project utilizes an ideographic-nomothetic measurement approach to determine whether individuals from two distinct samples are able to accomplish personality goals without the aid of therapeutic or experimenter involvement. In our follow-up assessments, we also measured retrospective conceptualizations of volitional personality change endeavors. The current effort was driven by three research questions:

1. Do those with or without a desire to change their personalities show different trajectories in each of the Big Five personality traits following the initial assessment?

2. Does the desire to change a specific trait predict actual change in this trait, when compared to the change exhibited by those without said trait change desire or desire to change any other trait?

3. Do those who do and do not perceive any personality change over the course of our studies show different trajectories in each of the Big Five personality traits during these periods?

To accomplish these aims, we recruited participants from two distinct different populations - an online, community-based sample and a sample of college students from a large public university in Southern California. The nature of these data allowed us to explore the volitional personality change process in a broad collection of individuals (our Internet sample) and those experiencing a particularly transformative period in life (our College student sample). In both samples, we utilized the aforementioned open-ended assessment of both desired personality change at our baseline assessment and perceived personality change at the follow-up assessment. We also measured changes in traits across 1-year (Internet sample) and 6-month (College student sample) timeframes. Here, the same open-ended response coding system reported by Baranski et al. (2017) was adopted. While we antici- pated coding participants' responses in terms of the volitional personality change dimensions that showed a substantial prevalence in Baranski et al. (2017) previous research (i.e., increases in Extraversion, Agreeableness, Conscientiousness, and Emotional Stability), we considered all 10 dimensions in their initial coding system (i.e., increases and decreases of each of the Big Five personality traits). We improved upon this original coding scheme with the addition of coding desires to increase or decrease each of the Big Five trait facets. For example, in addition to coding for desires to increase or decrease levels of Extraversion, we coded for desires to increase or decrease levels of sociability, energy, and assertiveness. We then sought to relate participant's personality change desires professed during our baseline assessment, as well as their perceived change at our follow-up assessment, to mean-level changes in personality traits over time.

\section{Method}

We report how we determined our sample size, all data exclusions, all manipulations, and all measures in the study.

\subsection{Participants}

\subsubsection{Internet sample}

Our Internet sample consisted of 530 participants $\left(M_{\text {age }}=41.5\right.$ years; $S D=12.60$ ) recruited via Amazon's Mechanical Turk, ${ }^{1}$ an online survey-based website (for discussion of the appropriateness of this source, see Buhrmester, Kwang, \& Gosling, 2011). 44\% of this sample was female, $10 \%$ self-identified as African American, $4 \%$ as Asian, $5 \%$ as Hispanic, $72 \%$ as White and $9 \%$ as other. This sample provided $92 \%$ power to detect average zero order effects. ${ }^{2}$ The data from the first assessment appears in Baranski et al. (2017, Study 2). 331 individuals participated in the first, but not the second, assessment (i.e., one year later), compared to the 204 participants who took part in both assessments (the 'missingness' of the data from Samples 1 and 2 is discussed below). Participants were paid $\$ 0.50$ each time they completed an assessment.

\subsubsection{College student sample}

Our second sample was drawn from a larger longitudinal study, The Riverside Assessment of Individual Lives Study (TRAILS). TRAILS consisted of two in-depth personality assessments taking place during the fall and spring quarters of the 2015/2016 school year (occurring approximately six months apart from one another). The total $N$ for this sample is $361\left(M_{a g e}=20.5\right.$ years, $\left.S D=3.18\right) .70 \%$ of this sample was female, $6 \%$ self-identified as African American, $34 \%$ as Asian, $42 \%$ as Hispanic, 5\% as White and 13\% as other. 213 students took part in the first, but not the second, assessment. This sample provided $74 \%$ power to detect the average zero order effect size present in the social/personality literature $(r \sim 0.21$; Funder \& Ozer, 1983). Participants were provided with the option of partial

\footnotetext{
1 There were no validity checks used for our Mturk sample. We did limit participation to those residing in the United States.

2 The present analyses use latent difference scores and full-information maximum likelihood (FIML) estimation for missing data, both of which make a-priori power estimations difficult. Presenting the average zero order effect power analysis, however, should give the reader some sense of the power associated with each study.

${ }^{3}$ Initially, we did not plan on conducting a second assessment of this sample. After beginning a similar lab study (our second sample in the current paper), however, we opted to conduct a follow-up with this Internet sample approximately one year after the initial wave of data collection. Operating through the Mturk data collection site, participants who took part in the Baranski et al. (2017) second study were contacted, reminded of their earlier participation, and asked to take part in a follow-up assessment. This revision to our initial study protocol was approved by the University of California, Riverside's Institutional Review Board (IRB).
} 
course credit or $\$ 25.00$ in exchange for their participation during each assessment.

\subsection{Procedure}

In both samples, at Time 1, participants were prompted to complete the 44-item Big Five Inventory (BFI; John \& Srivastava, 1999; Internet sample average $\alpha=0.89$; range $=0.82-0.94$; College student sample average $\alpha=0.76$; range $=0.72-0.81)^{4}$ and then indicate whether they were currently attempting to change an aspect of their personality. If they answered in the affirmative, they were then asked, in an open-ended format, to describe the aspect of their personalities they were trying to change (viz. "If you are trying to change, please describe the aspect of your personality you are interested in changing"). ${ }^{5}$ At Time 2, participants in both samples were again prompted to complete the 44-item BFI (Internet sample average $\alpha=0.80$; range $=0.78-0.82$; undergraduate sample average $\alpha=0.78$; range $=0.75-0.82$ ) and then asked, using a yes/no format, whether they thought an aspect of their personalities had changed since they last took part in the study (viz. "Has your personality changed in the last year?"). If participants answered in the affirmative the were then prompted for an open-ended description of the way(s) in which they thought their personalities had changed (viz. "Please explain the way(s) your personality has changed"). They were also prompted to complete a battery of individual difference inventories not relevant to the current study (see osf.io/bf4k6 for relevant study measures).

Finally, for our internet sample only, completed Carol Dweck's Implicit Theories of Personality Change (Chiu, Hong, \& Dweck, 1997). Specifically, participants rated the extent to which they agreed with statements regarding the individual's capacity to change their personalities (e.g., "People can't really change what kind of personality they have. Some people have a good personality and some don't and they can't change much"; Chiu et al., 1997). Participants also completed a series of asking them to rate their personality change desire along a revised version of Brian Little's Personal Project Analysis (e.g., "How important is changing this aspect of your personality at the present time?"; Little, 1983). At Time 2, we reminded participants of the desire they professed at Time 1 and again asked them to rate these desires according to Little's Personality Project Analysis (see osf.io/bf4k6 for study measures). ${ }^{6}$ Analyses with these two measures were not pertinent to our research questions, however, for the sake of transparency, we include models with these variables included as predictors for actual personality change in our Supplementary Materials (http://osf.io/ bf4k6).

\subsection{Coding of open-ended responses}

\subsubsection{Desired changes}

To develop an inclusive coding framework, we piloted a preliminary draft with two coders and roughly 300 responses from participants from a separate study with the same volitional personality change prompt. This original framework included increases/decreases of each the Big Five and their facets, as recognized in the BFI-2 (Soto \& John, 2017). For instance, the response "I would like

\footnotetext{
${ }^{4}$ The BFI was measured on a 7-point scale for the internet sample and a 5-point scale for the undergraduate sample.

5 Participants were explicitly prompted to indicate which aspect of their personalities they wished to change instead of a broader question about a desire to change themselves to limit desires about physical changes (e.g., losing weight) or changes in their life circumstances (e.g., getting a new job).

${ }^{6}$ During the consent process, we did not inform participants that their data would be open to the public. Data are available upon request.Also, this study was not preregistered and the analyses plan was not submitted to an independent institutional registry prior to data collection.
}

to be less shy" was coded as increased extraversion in accordance to the reversed-coded extraversion item on the BFI "is reserved". If a response did not fall into one of these categories, coders were instructed to mark them as falling into the 'other' category. After reviewing these responses, two additional categories were added: improving physical health and resolving an addiction (See osf.io/ bf4k6 for the coding manual). All total, the research assistant coders agreed that these categories captured $95.22 \%$ and $91.78 \%$ of the Internet and College student samples' responses, respectively. Responses falling in to the "Other" category included those that were vague or too broad to fit in to a trait category (e.g., "my character", "my entire personality").

Consistent with previous research (Baranski et al., 2017), in our main analyses, we considered only those categories observed in more than $10 \%$ of the sample. Categories pertaining to increases in Extraversion, the Extraversion facet of Sociability, Agreeableness, and Conscientiousness as well as increases in Emotional Stability and its facet of Anxiety (for the Internet sample only) met this threshold and the three coders were in sufficient agreement regarding their categorizations (Internet sample: average $\alpha=0.84$, range 0.97-0.42; College student sample: average $\alpha=0.83$, range $=0.96-0.64$; Table 3 ). See Table 1 examples of each form of desired change on the facet level.

\subsubsection{Perceived personality change}

We utilized the same 22-category coding procedure described above for participants' perceptions of personality change during the follow-up assessment. Here, coders agreed that the categories captured 64.71\% (Internet sample) and 87.5\% (College student sample) of participants' responses. Responses not captured included vague reports of change (e.g., "I feel like every year I become a slightly different person based on my experiences through life."), physical changes (e.g., "In July I nearly died from congestive heart failure, brought on by a chest cold."), or changes relating to religion (e.g., "Mostly in the area of my religious views. I have become very confused in what actually believe."). ${ }^{7}$ Coders had sufficient reliability for each of the most prevalent categories (Internet sample: $\alpha=0.74$, range 0.54-0.92; College student sample: $\alpha=0.81$, range $=0.66-0.92$ ). See Table 6 for examples of each form of desired change.

\subsection{Missing data}

$62 \%$ and $58 \%$ of the total Internet and College student sample did not return to complete the follow-up assessment, respectively. Due to this relatively high level of attrition, we determined whether there were substantial psychological or demographic differences between those who did, and did not, return for their follow-up assessments. In both of our samples, no significant differences were observed between those who did and did not return with respect to Conscientiousness, Emotional Stability, Openness to Experience, gender, or ethnicity (Cohen's d ranged from 0.008 to 0.23 ; p-levels ranged from 0.93 to 0.06 ). In both our College student and internet samples, however, there was a significant difference in mean levels of Extraversion between those who did and did not return at Time 2 in so far as those who returned had lower levels of Extraversion than non-returners ( $d s=0.24$ and 0.19 , $p s=0.04$ and 0.03 , respectively). Also, in our College student sample, those who completed the follow-up assessment had lower levels of Agreeableness when compared to those who did not return $(d=0.28, p=.03)$. Finally, in our Internet sample, older

\footnotetext{
${ }^{7}$ Due to the relatively small number of responses that fell in to each category, all subsequent analyses are conducted on the global level and any exploration at the facet level is strictly exploratory.
} 
Table 1

Sample desires for personality change and their associated conceptual categories.

\begin{tabular}{|c|c|}
\hline Desired Change & Example \\
\hline \multicolumn{2}{|l|}{ Increased Extraversion } \\
\hline Increased Sociability & I'd like to be more sociable. I get nervous in group settings and can't think of what to talk about. \\
\hline Increased Assertiveness & I would like to be able to be more outgoing, sociable, and assertive, and less reserved about what I say to people \\
\hline Increased Energy & I would like to more enthusiastic. \\
\hline \multicolumn{2}{|l|}{ Increased Agreeableness* } \\
\hline Increased Compassion & Sometimes I do not feel I have enough patience with my children. I would like to change that. \\
\hline Increase Trust & I would like to be more forgiving of people who offend me. \\
\hline \multicolumn{2}{|l|}{ Increased Conscientiousness } \\
\hline Increased Productivity & I procrastinate too much. \\
\hline Increased Responsibility & I would really like to change my timeliness. Like, being on time for stuff. \\
\hline Increased Organization & I am very disorganized and careless. \\
\hline \multicolumn{2}{|l|}{ Increased Emotional Stability } \\
\hline Increased Anxiety & I get anxious and worry too much, I would like to get that under control without relying on meds \\
\hline Increased Depression & I would like to be more positive minded. \\
\hline Increased Emotionality & I would like to be less angry. \\
\hline
\end{tabular}

" Note.Across studies, we did not observe an instance of Agreeableness' "Respect" factor. As such, it is not depicted in this table.

individuals were more likely to return at Time 2, when compared to their younger peers $(d=0.40, p<.001)$.

Missing data were handled using Full-Information Maximum Likelihood (FIML; Enders \& Bandalos, 2001). FIML is a method for estimating the latent difference score parameters using values from all variables in a model that are known and complete (specific model described below). FIML is the most widely used method for handling data missing completely at random and tends to perform better than ad-hoc procedures (e.g., pairwise or listwise deletion; Allison, 2003). It also yields more consistent solutions when compared to multiple imputation (Endler, 2017) due to deriving its estimates from participant-provided data.

FIML complements the latent difference score modeling outlined below, as FIML estimates structural parameters and standard errors while simultaneously handling missing data (Graham, 2009). Unlike imputation methods, FIML does not replace missing values, but rather deals with missingness as part of the model estimation procedure. To do so, FIML uses all available data to estimate the most likely population parameters. Furthermore, model estimates from FIML tend to be unbiased, even with large degrees of missingness (Graham, 2009).

For the present analyses, we utilized FIML to estimate change over time for all five traits given known and complete Time 1 trait values. A latent change score was estimated for each trait controlling for Time 1 trait levels values. The resulting pure change scores are the maximum likelihood estimates accounting for all missing data as outlined above.

\section{Results}

Changes in personality traits across time points were modeled using latent difference scores (Grimm, An, McArdle, Zonderman, \& Resnick, 2012; McArdle \& Hamagami, 2001). Rather than modeling raw differences in observed trait levels, latent difference scores model change while controlling for Time 1 trait levels, thus reflecting true change scores. In so doing, modeling true change ensures that the latent difference scores account for the measurement error present at both time points.

In what follows, we first examine the relation between desired and actual personality change in each of our samples. Following these preliminary analyses, we tested whether the desire to change any aspect of one's personality predicted actual trait change when compared to individuals with no desire to change said trait. Next, we determined whether the desire to change a specific trait predicted change in that or any other trait, compared to those without a desire to change and those with a desire to change any other trait.
The coefficients reported in the tables referenced below represent the standard deviation of the trait difference between participants with and without a personality change desire. Thus, they standardized coefficients representing personality change as a function of having a personality change desire.

Finally, in an effort to understand conceptualization of the entire volitional personality change process, we explored the relation between perceptions of personality trait change and actual personality change. Specifically, we assessed whether actual change predicted the perception of any personality change at the follow-up assessment.

3.1. Do those with or without a desire to change their personalities show different trajectories in each of the Big Five personality traits following the initial assessment?

Using FIML, we ran a series of tests that modeled trait change from Time 1 to Time 2 as a latent variable and computed average latent difference scores across each sample for each trait to assess baseline trait change over time (see Table 2). Levels of Extraversion significantly increased in the Internet sample $(M=0.11 ; p<.001)$ and College student sample $(M=0.12 ; p=.03)$. This effect, however, should be interpreted with caution, given that, in both samples, those who did and did not return for our follow-up assessment were found to differ on Extraversion. In our Internet sample, there was also a significant decrease in levels of Openness to Experience $(M=-0.07 ; p=.04)$.

While we did not observe much trait change from Time 1 to Time 2, at an individual level there was significant variation in latent change for all five traits (see $\sigma^{2}$ columns of Table 2). This indicates that there was variability with respect to whether participants changed in the first place and, if they did, the direction in which this change manifested. For example, although meanlevels of Agreeableness did not differ across time points, we observed between-subject variability in the degree of change. Some participants increased in this trait, others decreased, and others still maintained consistency across assessment periods.

3.2. Does the desire to change a specific trait predict actual change in this trait, when compared to the change exhibited by those without said trait change desire or any desire to change?

Across both samples, the majority of participants indicated a desire to increase in Extraversion, Conscientiousness and Emotional Stability. On the facet level, the majority of participants with a desire to increase Extraversion sought to be more social, those 
Table 2

Personality trait mean latent difference scores between initial and follow-up trait assessments.

\begin{tabular}{|c|c|c|c|c|c|c|}
\hline & \multicolumn{3}{|c|}{ Internet sample } & \multicolumn{3}{|c|}{ College student sample } \\
\hline & $M$ & $p$-level & $\sigma^{2}$ & $M$ & $p$-level & $\sigma^{2}$ \\
\hline Extraversion & 0.11 & $<.001$ & 0.15 & 0.12 & .03 & 0.41 \\
\hline Conscientiousness & -0.001 & .97 & 0.26 & 0.05 & .39 & 0.51 \\
\hline Agreeableness & -0.04 & .19 & 0.22 & 0.03 & .72 & 0.65 \\
\hline Emotional Stability & 0.04 & .24 & 0.23 & -0.01 & .87 & 0.44 \\
\hline Openness & -0.07 & .04 & 0.25 & 0.00 & 1.00 & 0.60 \\
\hline
\end{tabular}

Note. $N_{\text {internet }}=204 ; N_{\text {college student }}=151$.

Table 3

Percentage and coding reliability of volitional personality change categories.

\begin{tabular}{|c|c|c|c|c|}
\hline & \multicolumn{2}{|c|}{ Internet sample } & \multicolumn{2}{|c|}{ College student sample } \\
\hline & $\%$ of responses & $\alpha$ & $\%$ of responses & $\alpha$ \\
\hline Inc. Extraversion & 35.29 & 0.97 & 32.37 & 0.96 \\
\hline Inc. Sociability & 26.84 & 0.95 & 30.43 & 0.96 \\
\hline Inc. Energy & 1.47 & 0.89 & 0.00 & - \\
\hline Inc. Assertiveness & 6.99 & 0.92 & 1.93 & 0.65 \\
\hline Inc. Agreeableness & 12.50 & 0.92 & 15.94 & 0.91 \\
\hline Inc. Compassion & 7.35 & 0.87 & 10.63 & 0.87 \\
\hline Inc. Respect & 0.00 & - & 0.00 & - \\
\hline Inc. Trust & 2.57 & 0.79 & 3.38 & 0.71 \\
\hline Inc. Conscientiousness & 16.18 & 0.96 & 14.01 & 0.96 \\
\hline Inc. Organization & 2.21 & 0.89 & 0.97 & 0.70 \\
\hline Inc. Productive & 9.93 & 0.90 & 7.73 & 0.95 \\
\hline Inc. Responsible & 3.31 & 0.88 & 4.83 & 0.82 \\
\hline Inc. Emotional Stability & 25.00 & 0.93 & 21.26 & 0.88 \\
\hline Dec. Anxiety & 12.87 & 0.92 & 6.28 & 0.79 \\
\hline Dec. Depression & 6.25 & 0.78 & 8.70 & 0.64 \\
\hline Dec. Emotionality & 4.78 & 0.87 & 4.83 & 0.69 \\
\hline Inc. Openness & 1.10 & 0.64 & 2.90 & 0.83 \\
\hline Inc. Intellect & 0.00 & - & 0.97 & - \\
\hline Inc. Aesthetic & 0.00 & - & 0.00 & - \\
\hline Inc. Creative & 1.10 & 0.83 & 0.00 & - \\
\hline Physical change & 0.37 & 0.90 & 0.00 & - \\
\hline Addiction & 0.74 & 0.80 & 0.00 & - \\
\hline Dec Extraversion & 0.00 & - & 0.00 & - \\
\hline Dec Sociability & 0.00 & - & 0.00 & - \\
\hline Dec Energy & 0.00 & - & 0.00 & - \\
\hline Dec Assertiveness & 0.00 & - & 0.00 & - \\
\hline Dec Agreeableness & 3.30 & 0.91 & 5.31 & 0.86 \\
\hline Dec Compassion & 2.57 & 0.87 & 4.35 & 0.87 \\
\hline Dec Respect & 0.00 & - & 0.00 & - \\
\hline Dec Trust & 0.37 & 0.82 & 0.00 & - \\
\hline Dec Conscientiousness & 0.74 & 0.42 & 0.00 & - \\
\hline Dec Organization & 0.00 & - & 0.00 & - \\
\hline Dec Productive & 0.37 & - & 0.00 & - \\
\hline Dec Responsible & 0.37 & 0.57 & 0.00 & - \\
\hline Dec Emotional Stability & 0.00 & - & 0.00 & - \\
\hline Inc Anxiety & 0.00 & - & 0.00 & - \\
\hline Inc Depression & 0.00 & - & 0.00 & - \\
\hline Inc Emotionality & 0.00 & - & 0.00 & - \\
\hline Dec Openness & 0.00 & - & 0.00 & - \\
\hline Dec Intellect & 0.00 & - & 0.00 & - \\
\hline Dec Aesthetic & 0.00 & - & 0.00 & - \\
\hline Dec Creative & 0.00 & - & 0.00 & - \\
\hline
\end{tabular}

Table 4

Desired personality change predicting actual trait change (comparisons between those who did and did not indicate a desire to change any trait).

\begin{tabular}{lccccc}
\hline \multirow{2}{*}{ Trait change } & \multicolumn{2}{c}{ Internet sample } & & \multicolumn{2}{c}{$\begin{array}{c}\text { College student } \\
\text { sample }\end{array}$} \\
\cline { 2 - 3 } \cline { 5 - 6 } & $\mathrm{B}$ & p-level & & $\mathrm{B}$ & p-level \\
\hline Extraversion & -0.11 & .45 & & -0.003 & .98 \\
Conscientiousness & -0.14 & .33 & & -0.07 & .60 \\
Agreeableness & -0.04 & .78 & & 0.13 & .33 \\
Emotional stability & -0.17 & .25 & & -0.13 & .37 \\
Openness & -0.01 & .93 & & -0.11 & .42 \\
\hline
\end{tabular}

with a desire to be more Conscientious sought to be more productive and those with a desire to increase in Emotional Stability sought to be less anxious and depressed (see Table 3 for a breakdown in proportions of each trait and facet for each sample). As indicated in Table 4, for both samples, the global desire for personality change (i.e., answering 'yes' to the survey question "Is there as aspect of your personality that you're currently trying to change?"), did not predict actual change for any personality trait ( $p s \geq 0.25$ ).

While a global desire to change did not predict actual change, it may be the case that a specific change goal predicted subsequent personality change. To systematically test this possibility, we next 
assessed whether desires to change a specific trait predicted actual change, both in comparison to those without a change goal, and to those with a goal to change any other trait. We chose to use both comparison groups in order to help understand the mechanism of successful (or unsuccessful) personality change. For instance, individuals with personality change goals may be especially likely to change relative to someone who is not working on any personality change whatsoever. Alternatively, it may be true that individuals with personality change goals are more likely to change as compared to someone who has personality change goals but is putting their efforts elsewhere.

\subsubsection{Comparisons among those with a specific trait change goal and those without a change goal}

We ran a series of structural equation models (SEMs) to test whether the desire to change a particular trait, or the dominate facet(s) for each trait (e.g., sociability for Extraversion, anxiety and depression for Emotional Stability), predicted actual trait change in any and all traits, when compared to individuals who did not report a desire for personality change (see Fig. 1 for a visual representation of SEM analyses). As indicated in Tables $5 a-5 d$, in our Internet sample, desired trait change did not predict actual trait change. In our College student sample, in line with Robinson et al. (2015). when compared to individuals who did not want to change any aspect of their personalities, those with a desire to increase levels of Conscientiousness exhibited greater decreases in this trait ( $\mathrm{B}=-0.45 ; p=.05)$. It should be noted that given its counterintuitive nature, and relative high chance at Type I error, this effect should be interpreted with caution. Indeed, this effect, and others similarly close approach to $p=.05$, may not remain significant if it were subject to more strenuous error controls.

\subsubsection{Comparisons among those with a specific trait change goal and those with a different change goal}

To further understand whether desired trait change predicted actual change, we next compared changes in personality traits among those who desired to change a particular trait with those who desired to change any other trait.

Under these conditions, desired change did not predict actual change in our Internet sample (Tables 6a-6d). In contrast, in the College student sample, there was a number of significant corresponding (i.e., the desire to increase Extraversion predicting change in Extraversion) and non-corresponding (i.e., the desire to increase Extraversion prediction change in Agreeableness) relations. First, the desire to increase levels of Extraversion predicted subsequent decreases in Extraversion ( $\mathrm{B}=-0.37, p=.05$ ). Likewise, the desire to increase Agreeableness predicted decreases in Agreeableness $(\mathrm{B}=-0.50 ; p=.01)$. There were also a few instances in the College student sample in which desired change for one trait predicted actual change in a non-corresponding trait. Specifically, the desire to increase levels of Extraversion and its facet Sociability predicted subsequent increases in Agreeableness $(\mathrm{B}=0.33 ; p=.04 ; \mathrm{B}=0.33$; $p=.04$, respectively) and Emotional Stability $(\mathrm{B}=0.37 ; p=.05$; $\mathrm{B}=0.40 ; p=.04$, respectively). Again, given the counterintuitive nature of these findings and chance at Type I error, the effects reported here should be interpreted with caution. This caution applies most notably to the effects that barely cross the threshold of significance (e.g., the inverse relationship between desires to increase Extraversion and subsequent changes in that trait).

3.3. Do those who do and do not perceive personality change over the course of our studies show different trajectories in each of the Big Five traits?

Results reported thus far suggest that individuals from both university and non-university communities, when left to their

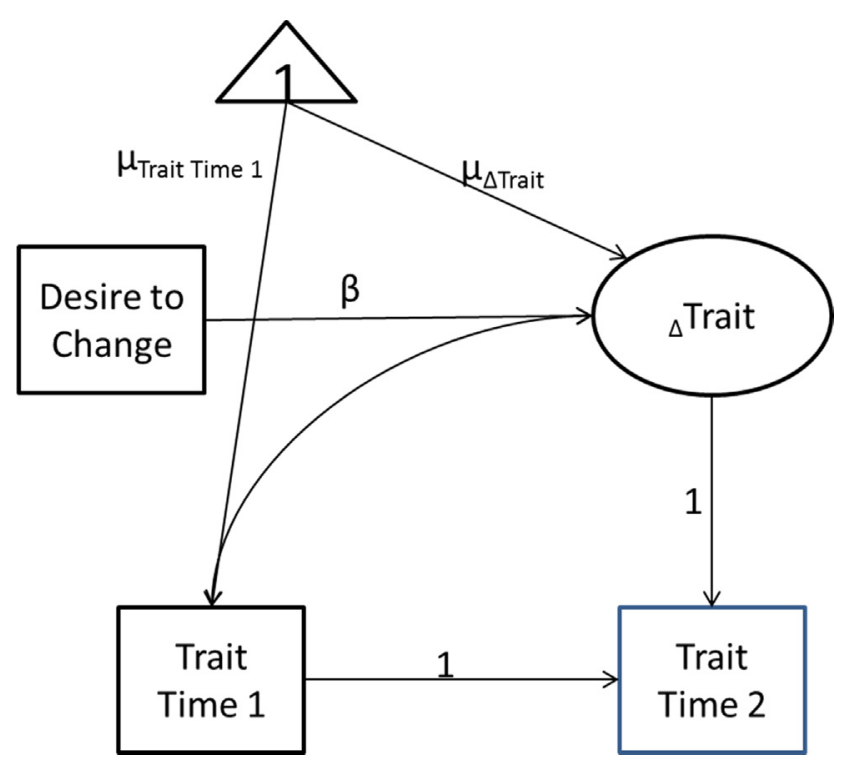

Fig. 1. Visual representation of SEM analyses.

own devices, are largely unable to achieve their personality change goals. Indeed, when change did occur in our samples, it was either in the opposite direction than was intended or corresponded with an increase in a different trait entirely. In an effort to understand the conceptualization of the entire volitional personality change process and try to gain insight in these trends, we next explored whether individuals are aware of this inability to follow through with personality change desires.

For those who had an initial desire to change their personalities, $12.5 \%$ (Internet sample) and $20.77 \%$ (College student sample) believed that their personalities had changed in some manner since the study's initial assessment. There was a moderate relationship between an initial desire to change any trait and the perception of any change at follow-up (Internet sample: $r=0.14$; $p=.05$; College student sample: $r=0.14 ; p=.08$ ). We next ran a series of tests to assess whether actual change since the initial assessment period predicted the perception of change for any trait (i.e., answering 'yes' to the question "Has your personality changed in the last year?"). Although these analyses are constrained by comparably small cell sizes, we did observe that individuals from our college student sample who perceived they had changed became less Emotionally Stable during that period (see Table 7). Additionally, even though participants from both samples were largely unsuccessful in their ambitions for volitional personality change, of those with initial desires to change, 22.27\% (Internet sample) and $30.43 \%$ (College student sample) indicated they wished to change at the follow-up assessment.

Due to the small sample size of those who perceived change at the follow-up assessment, correlational or regression analyses with our trait-level data is not advisable. Descriptively, however, among those who perceived personality change since the study's initial assessment, the majority of participants perceived personality change over the previous year in the socially desirable direction. Specifically, in our Internet sample, participants reported that they had become more Extraverted (17.65\%; specifically, more social), Agreeable (11.76\%; specifically, more compassionate) and Emotionally Stable (8.82\%; specifically, less anxious and depressed). In contrast, for our college student sample, the majority of participants reported that they had become more Agreeable (14.06\%, specifically more compassionate), Emotionally Stable (23.44\%, specifically less anxious and depressed) and Conscientious (23.44\%; specifically, more responsible). Finally, in both samples 
Table 5a

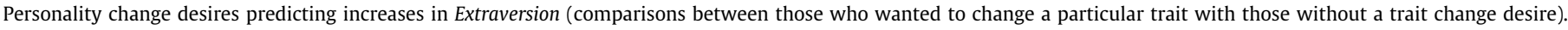

\begin{tabular}{|c|c|c|c|c|}
\hline \multirow[b]{2}{*}{ Desired trait change } & \multicolumn{2}{|c|}{ Internet sample } & \multicolumn{2}{|c|}{ College student sample } \\
\hline & $\mathrm{B}[95 \% \mathrm{CI}]$ & $p$ & $\mathrm{~B}[95 \% \mathrm{CI}]$ & $p$ \\
\hline Inc Extraversion & $-0.32[-0.68,0.05]$ & .09 & $-0.27[-0.59,0.06]$ & .11 \\
\hline Inc Sociability & $-0.34[-0.73,0.05]$ & .09 & $-0.30[-0.63,0.03]$ & .07 \\
\hline Inc Agreeableness & $0.04[-0.56,0.64]$ & .90 & $0.08[-0.37,0.53]$ & .74 \\
\hline Inc Compassion & $-0.05[-0.70,0.59]$ & .87 & $0.13[-0.40,0.65]$ & .64 \\
\hline Inc Conscientiousness & $-0.22[-0.74,0.29]$ & .39 & $-0.12[-0.65,0.40]$ & .65 \\
\hline Inc Productive & $-0.23[-0.84,0.39]$ & .50 & $-0.12[-0.82,0.59]$ & .75 \\
\hline Inc Emotional Stability & $-0.03[-0.41,0.36]$ & .90 & $0.19[-0.26,0.63]$ & .41 \\
\hline Dec Anxiety & $0.04[-0.45,0.52]$ & .88 & $0.19[-0.26,0.63]$ & .14 \\
\hline Dec Depression & $-0.07[-0.67,0.54]$ & .83 & $-*$ & $-*$ \\
\hline
\end{tabular}

Note. $N_{\text {internet }}=530 ; N_{\text {college student }}=361$

the College student sample did not include any responses categorized as Decreased Depression.

Table 5b

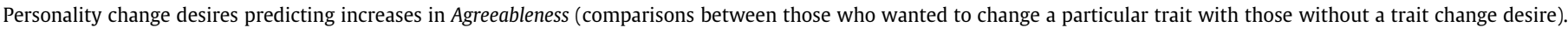

\begin{tabular}{|c|c|c|c|c|}
\hline \multirow[b]{2}{*}{ Desired trait change } & \multicolumn{2}{|c|}{ Internet sample } & \multicolumn{2}{|c|}{ College student sample } \\
\hline & B $[95 \% \mathrm{CI}]$ & $p$ & B $[95 \% \mathrm{CI}]$ & $p$ \\
\hline Inc Extraversion & $-0.02[-0.37,0.33]$ & .90 & $0.35[-0.009,0.70]$ & .06 \\
\hline Inc Sociability & $0.00[-0.39,0.39]$ & 1.00 & $0.36[-0.01,0.72]$ & .06 \\
\hline Inc Agreeableness & $-0.21[-0.82,0.41]$ & .51 & $-0.19[-0.67,0.30]$ & .45 \\
\hline Inc Compassion & $-0.21[-0.90,0.49]$ & .56 & $-0.13[-0.75,0.48]$ & .67 \\
\hline Inc Conscientiousness & $-0.04[-0.59,0.52]$ & .90 & $-0.14[-0.76,0.47]$ & .64 \\
\hline Inc Productive & $-0.09[-0.76,0.58]$ & .80 & $-0.20[-.-0.47,-0.15]$ & .62 \\
\hline Inc Emotional Stability & $0.04[-0.40,0.47]$ & .88 & $0.09[0.71,-0.37]$ & .71 \\
\hline Dec Anxiety & $0.05[-0.05,0.56]$ & .87 & $0.31[0.41,-0.42]$ & .41 \\
\hline Dec Depression & $0.01[-0.64,0.62]$ & .97 & $-^{*}$ & $-*$ \\
\hline
\end{tabular}

Table 5c

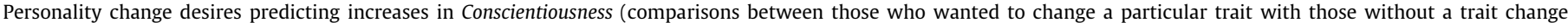
desire).

\begin{tabular}{|c|c|c|c|c|}
\hline \multirow[b]{2}{*}{ Desired trait change } & \multicolumn{2}{|c|}{ Internet sample } & \multicolumn{2}{|c|}{ College student sample } \\
\hline & $\mathrm{B}[95 \% \mathrm{CI}]$ & $p$ & B $[95 \% \mathrm{CI}]$ & $p$ \\
\hline Inc Extraversion & $-0.19[-0.52,0.14]$ & .25 & $-0.01[-0.38,0.37]$ & .96 \\
\hline Inc Sociability & $-0.12[-0.48,0.23]$ & .50 & $-0.01[-0.40,0.38]$ & .96 \\
\hline Inc Agreeableness & $-0.05[-0.62,0.52]$ & .86 & $-0.17[-0.62,0.29]$ & .47 \\
\hline Inc Compassion & $-0.19[-0.82,0.45]$ & .57 & $-0.16[-0.70,0.37]$ & .56 \\
\hline Inc Conscientiousness & $-0.12[-0.65,0.41]$ & .67 & $-0.45[-0.59,-0.31]$ & .05 \\
\hline Inc Productive & $-0.39[-1.04,0.25]$ & .23 & $-0.46[-1.16,0.25]$ & .20 \\
\hline Inc Emotional Stability & $-0.11[-0.52,0.29]$ & .58 & $-0.03[-0.45,0.39]$ & .88 \\
\hline Dec Anxiety & $-0.18[-0.70,0.34]$ & .50 & $-0.06[-0.72,0.61]$ & .87 \\
\hline Dec Depression & $0.05[-0.52,0.62]$ & .86 & $-^{*}$ & $-*$ \\
\hline
\end{tabular}

Note. $N_{\text {internet }}=530 ; N_{\text {college student }}=361$.

the College student sample did not include any responses categorized as Decreased Depression.

Table 5d

Personality change desires predicting increases in Emotional Stability (comparisons between those who wanted to change a particular trait with those without a trait change desire).

\begin{tabular}{|c|c|c|c|c|}
\hline \multirow[b]{2}{*}{ Desired trait change } & \multicolumn{2}{|c|}{ Internet sample } & \multicolumn{2}{|c|}{ College student sample } \\
\hline & $\mathrm{B}[95 \% \mathrm{CI}]$ & $p$ & В $[95 \% \mathrm{CI}]$ & $p$ \\
\hline Inc Extraversion & $0.23[-0.13,0.59]$ & .22 & $0.15[-0.52,0.22]$ & .43 \\
\hline Inc Sociability & $0.20[-0.21,0.60]$ & .35 & $0.17[-0.56,0.21]$ & .37 \\
\hline Inc Compassion & $0.25[-0.43,0.94]$ & .47 & $-0.27[-0.34,0.88]$ & .39 \\
\hline Inc Conscientiousness & $0.09[-0.45,0.63]$ & .75 & $-0.37[-0.21,0.98]$ & .21 \\
\hline Inc Productive & $0.12[-0.56,0.80]$ & .76 & $0.02[-0.80,0.76]$ & .96 \\
\hline Inc Emotional Stability & $0.26[-0.21,0.70]$ & .28 & $-0.37[-0.07,0.80]$ & .10 \\
\hline
\end{tabular}

Note. $N_{\text {internet }}=530 ; N_{\text {college student }}=361$.

the College student sample did not include any responses categorized as Decreased Depression 
Table 6a

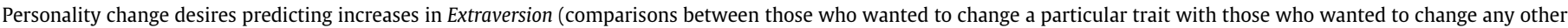
trait).

\begin{tabular}{|c|c|c|c|c|}
\hline \multirow[b]{2}{*}{ Desired trait change } & \multicolumn{2}{|c|}{ Internet sample } & \multicolumn{2}{|c|}{ College student sample } \\
\hline & $\mathrm{B}[95 \% \mathrm{CI}]$ & $p$ & $\mathrm{~B}[95 \% \mathrm{CI}]$ & $p$ \\
\hline Inc Extraversion & $-0.17[-0.55,0.21]$ & .37 & $-0.37[-0.73,0.005]$ & .05 \\
\hline Inc Sociability & $-0.17[-0.57,0.023]$ & .45 & $-0.40[-0.78,-0.029]$ & .04 \\
\hline Inc Agreeableness & $-0.09[-0.80,0.63]$ & .82 & $0.07[-0.42,0.55]$ & .74 \\
\hline Inc Compassion & $-0.12[-0.84,0.60]$ & .74 & $0.13[-0.46,0.71]$ & .67 \\
\hline Inc Conscientiousness & $-0.08[-0.59,0.43]$ & .76 & $-0.13[-0.70,0.46]$ & .67 \\
\hline Inc Productive & $0.07[-0.56,0.71]$ & .83 & $-0.11[-0.89,0.66]$ & .78 \\
\hline Inc Emotional Stability & $0.16[-0.22,0.56]$ & .40 & $0.25[-0.18,0.69]$ & .26 \\
\hline Dec Anxiety & $0.17[-0.30,0.65]$ & .47 & $0.52[-0.18,1.2]$ & .15 \\
\hline Dec Depression & $0.17[-0.46,0.78]$ & .50 & $-0.25[0.91,403]$ & .45 \\
\hline
\end{tabular}

Note. $N_{\text {internet }}=530 ; N_{\text {college student }}=361$.

Table $6 b$

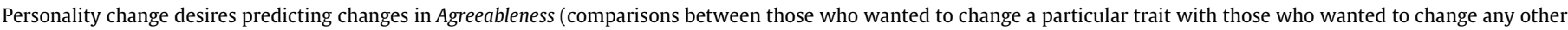
trait).

\begin{tabular}{|c|c|c|c|c|}
\hline \multirow[b]{2}{*}{ Desired trait change } & \multicolumn{2}{|c|}{ Internet sample } & \multicolumn{2}{|c|}{ College student sample } \\
\hline & $\mathrm{B}[95 \% \mathrm{CI}]$ & $p$ & В $[95 \% \mathrm{CI}]$ & $p$ \\
\hline Inc Extraversion & $0.09[-0.27,0.44]$ & .62 & $0.33[0.01,0.64]$ & .04 \\
\hline Inc Sociability & $0.09[-0.28,0.46]$ & .63 & $0.33[0.01,0.66]$ & .04 \\
\hline Inc Agreeableness & $-0.20[-0.79,0.39]$ & .50 & $-0.50[-0.89,-0.10]$ & .01 \\
\hline Inc Compassion & $-0.21[-0.88,0.46]$ & .54 & $-0.35[-0.86,0.12]$ & .14 \\
\hline Inc Conscientiousness & $-0.05[-0.56,0.45]$ & .84 & $-0.24[-0.74,0.26]$ & .35 \\
\hline Inc Productive & $-0.12[-0.73,0.50]$ & .71 & $-0.32[-0.98,0.33]$ & .33 \\
\hline Inc Emotional Stability & $-0.01[-0.39,0.39]$ & .97 & $-0.02[-0.40,0.35]$ & .91 \\
\hline Dec Anxiety & $0.07[-0.40,0.54]$ & .77 & $0.22[-0.38,0.82]$ & .45 \\
\hline Dec Depression & $-0.04[-0.65,0.58]$ & .91 & $-0.27[-0.83,0.26]$ & .34 \\
\hline
\end{tabular}

Note. $N_{\text {internet }}=530 ; N_{\text {college student }}=361$.

Table 6c

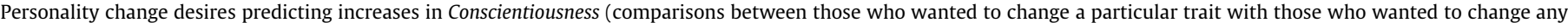
other trait)

\begin{tabular}{|c|c|c|c|c|}
\hline \multirow[b]{2}{*}{ Desired trait change } & \multicolumn{2}{|c|}{ Internet sample } & \multicolumn{2}{|c|}{ College student sample } \\
\hline & $\mathrm{B}[95 \% \mathrm{CI}]$ & $p$ & B $[95 \% \mathrm{CI}]$ & $p$ \\
\hline Inc Extraversion & $-0.02[-0.35,0.31]$ & .90 & $0.10[-0.26,0.46]$ & .58 \\
\hline Inc Sociability & $-0.09[-0.27,0.44]$ & .63 & $0.10[-0.27,0.46]$ & .60 \\
\hline Inc Agreeableness & $0.05[-0.54,64]$ & .87 & $-0.12[-0.59,34]$ & .60 \\
\hline Inc Compassion & $-0.09[-0.75,0.56]$ & .79 & $-0.10[-0.65,0.46]$ & .73 \\
\hline Inc Conscientiousness & $0.09[-0.42,0.60]$ & .74 & $-0.48[-1.02,0.06]$ & .08 \\
\hline Inc Productive & $-0.19[-0.79,0.42]$ & .54 & $-0.40[-1.11,0.32]$ & .28 \\
\hline Inc Emotional Stability & $-0.02[-0.38,0.34]$ & .93 & $0.05[-0.37,0.47]$ & .82 \\
\hline Dec Anxiety & $-0.13[-0.58,0.32]$ & .57 & $0.03[-0.64,0.70]$ & .93 \\
\hline Dec Depression & $0.21[-0.37,0.79]$ & .48 & $0.07[-0.56,0.69]$ & .84 \\
\hline
\end{tabular}

Note. $N_{\text {internet }}=530 ; N_{\text {college student }}=361$.

Table 6d

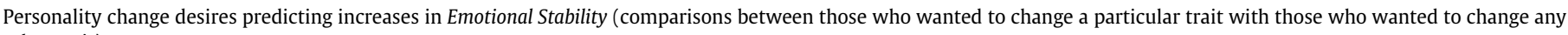
other trait).

\begin{tabular}{|c|c|c|c|c|}
\hline \multirow[b]{2}{*}{ Desired trait change } & \multicolumn{2}{|c|}{ Internet sample } & \multicolumn{2}{|c|}{ College student sample } \\
\hline & B $[95 \% \mathrm{CI}]$ & $p$ & B $[95 \% \mathrm{CI}]$ & $p$ \\
\hline Inc Extraversion & $-0.05[-0.29,0.38]$ & .79 & $0.37[-0.73,-0.007]$ & .05 \\
\hline Inc Sociability & $-0.02[-0.34,0.38]$ & .91 & $0.40[-0.76,-0.03]$ & .04 \\
\hline Inc Agreeableness & $0.003[-0.59,0.58]$ & .99 & $-0.30[-0.19,0.75]$ & .25 \\
\hline Inc Compassion & $-0.10[-0.55,0.76]$ & .76 & $-0.17[-0.40,0.75]$ & .56 \\
\hline Inc Conscientiousness & $0.07[-0.56,0.42]$ & .79 & $-0.33[-0.25,90]$ & .27 \\
\hline Inc Productive & $-0.02[-0.58,0.62]$ & .95 & $0.12[-0.88,0.64]$ & .76 \\
\hline Inc Emotional Stability & $-0.16[-0.22,0.54]$ & .41 & $-0.27[-0.16,0.70]$ & .22 \\
\hline Dec Anxiety & $0.06[-0.53,0.41]$ & .80 & $-0.37[-0.32,1.05]$ & .29 \\
\hline Dec Depression & $-0.30[-0.30,0.90]$ & .33 & $-0.18[-0.47,0.82]$ & .60 \\
\hline
\end{tabular}

Note. $N_{\text {internet }}=530 ; N_{\text {college student }}=361$. 
Table 7

Percentage and coding reliability of perceptions of change at follow up assessment.

\begin{tabular}{|c|c|c|c|c|}
\hline & \multicolumn{2}{|c|}{ Internet sample } & \multicolumn{2}{|c|}{ College student sample } \\
\hline & $\%$ of responses & $\alpha$ & $\%$ of responses & $\alpha$ \\
\hline Inc Extraversion & 17.65 & 0.76 & 7.81 & 0.86 \\
\hline Inc Sociability & 17.65 & 0.76 & 3.13 & 0.81 \\
\hline Inc Energy & 0.00 & - & 0.00 & \\
\hline Inc Assertiveness & 0.00 & - & 1.56 & 0.46 \\
\hline Inc Agreeableness & 11.76 & 0.75 & 14.06 & 0.66 \\
\hline Inc Compassion & 2.94 & 0.46 & 4.69 & 0.56 \\
\hline Inc Respect & 0.00 & - & 0.00 & - \\
\hline Inc Trust & 0.00 & - & 0.00 & - \\
\hline Inc Conscientiousness & 5.88 & 0.84 & 23.44 & 0.89 \\
\hline Inc Organization & 0.00 & - & 3.13 & 0.58 \\
\hline Inc Productive & 5.88 & 0.92 & 4.69 & 0.96 \\
\hline Inc Responsible & 0.00 & - & 10.94 & 0.74 \\
\hline Inc Emotional Stability & 8.82 & 0.78 & 23.44 & 0.74 \\
\hline Dec Anxiety & 2.94 & 0.82 & 4.69 & 0.46 \\
\hline Dec Depression & 2.94 & 0.82 & 12.50 & 0.72 \\
\hline Dec Emotionality & - & 0.81 & 0.00 & - \\
\hline Inc Openness & 0.00 & - & 3.13 & 0.80 \\
\hline Inc Intellect & 0.00 & - & 1.56 & 0.57 \\
\hline Inc Aesthetic & 0.00 & - & 0.00 & - \\
\hline Inc Creative & 0.00 & - & 1.56 & 1.00 \\
\hline Physical change & 0.00 & - & 0.00 & - \\
\hline Addiction & 0.00 & - & 0.00 & - \\
\hline Dec Extraversion & 8.82 & 0.54 & 3.13 & 0.81 \\
\hline Dec Sociability & 5.88 & 0.64 & 3.13 & 0.92 \\
\hline Dec Energy & 0.00 & - & 0.00 & - \\
\hline Dec Assertiveness & 0.00 & - & 0.00 & - \\
\hline Dec Agreeableness & 2.94 & 0.29 & 6.25 & 0.85 \\
\hline Dec Compassion & 2.94 & 0.46 & 4.69 & 0.56 \\
\hline Dec Respect & 0.00 & - & 0.00 & - \\
\hline Dec Trust & 0.00 & - & 0.00 & - \\
\hline Dec Conscientiousness & 0.00 & - & 0.00 & - \\
\hline Dec Organization & 0.00 & - & 0.00 & - \\
\hline Dec Productive & 0.00 & - & 0.00 & - \\
\hline Dec Responsible & 0.00 & - & 0.00 & - \\
\hline Dec Emotional Stability & 8.82 & 0.54 & 6.25 & 0.81 \\
\hline Inc Anxiety & 2.94 & 0.29 & 0.00 & - \\
\hline Inc Depression & 5.88 & 0.49 & 6.25 & 0.92 \\
\hline Inc Emotionality & 0.00 & - & 0.00 & - \\
\hline Dec Openness & 0.00 & - & 0.00 & - \\
\hline Dec Intellect & 0.00 & - & 0.00 & - \\
\hline Dec Aesthetic & 0.00 & - & 0.00 & - \\
\hline Dec Creative & 0.00 & - & 0.00 & - \\
\hline Other & 11.74 & 0.76 & 3.13 & 0.86 \\
\hline
\end{tabular}

and contrary to initial personality change desires, a relatively large percentage perceived that they had become less Emotionally Stable (Internet sample: $8.82 \%$; College student sample: $6.25 \%$ ).

\section{Discussion}

Despite widespread recognition that personality traits change over the lifespan (Roberts \& Mroczek, 2008; Roberts, Robins, Trzesniewski \& Caspi, 2003; Roberts, Walton, \& Viechtbauer, 2006; Robins, Fraley, Roberts, \& Trzesniewski, 2001; Srivastava, John, Gosling, \& Potter, 2003), little attention has been given to the investigation of volitional personality change - or the active and purposeful role individuals may play in their own personality development (Baranski et al., 2017; Hudson \& Fraley, 2015; Robinson et al., 2015). Among the studies that have explored this process, findings have been mixed insofar as those that frequently remind participants of their personality change goals find a positive relationship between trait change goals and actual (viz. selfreported) trait change, whereas those without any regular follow-up assessments find a negative relation between the motivation to change a trait and subsequent levels of this trait (Hudson \& Fraley, 2015, 2016; Robinson et al., 2015).

To contribute to this emerging literature, we explored volitional personality change via the application of an ideographic- nomothetic assessment method across two demographically distinct samples. Because we did not contact participants until the follow-up assessment, we were able to assess whether individuals with personality change goals experience actual change when left to their own devices. We first assessed whether these desires related to actual personality change over a 1 -year (Internet sample) or 6-month (College student sample) time frame. To thoroughly and systematically examine the relation between desired and actual personality change, we compared personality change among: (1) those who did and did not exhibit a desire to change their personalities; (2) those who had a desire to change a specific trait and those without a personality change desire; (3) those who had a desire to change a specific trait and those who had a desire to change a different trait. We then sought to address whether individuals are accurate regarding their perceptions of their personality change pursuits.

\subsection{Desired and actual personality change}

Replicating previous work (e.g., Baranski et al., 2017; Hudson \& Roberts, 2014; Hudson \& Fraley, 2015), the majority of participants from both internet and college populations indicated a desire to change an aspect of their personalities, specifically to increase levels of Extraversion (i.e., sociability), Conscientiousness (i.e., 
productive) and Emotional Stability (i.e., less anxious and depressed). Replicating Robinson et al. (2015), in our college sample, a desire to increase levels of Conscientiousness predicted change in the opposite direction. In other words, those with the strongest desires to increase levels of Conscientiousness exhibited the greatest decreases in this trait over the six-month study period, when compared to those without personality change goals. Adopting the explanation provided by Robinson and colleagues (2015), participants who wanted to be more conscientious at the initial assessment period tended to have low levels of this trait, which may have put them at a disadvantage at the outset in accomplishing this goal. Moreover, in our college student sample, individuals working to be more Extraverted (specifically, more social), tended to become less extraverted over the 6-month study period when compared to those with a different change goal. The same pattern was observed when Agreeableness was considered. These findings may be due to the disconnect between how individuals describe personality change desires, and the behaviors they invoke to accomplish these goals (see below for a thorough analysis of this possibility).

It may be the case that our participants were expressing cursory personality change desires that were given less priority relative to more concrete goals (e.g., making money, doing well on an exam, losing weight; Miller et al., 2019). Personality change is a goal that most people have (Baranski et al., 2017, Hudson \& Fraley, 2015, 2016), yet because there are not often explicit outcomes to achieving such a goal, individuals may put more efforts towards goals that lead to more tangible outcomes. Unlike other studies that have found corresponding desired-actual personality change associations (Hudson \& Fraley, 2015, 2016), participants in our studies were not regularly reminded of the change goals. As a result, they may have prioritized goal pursuit efforts towards non-personality related endeavors.

Alternatively, participants may have misdirected their personality change efforts. Indeed, in our college student sample, there were a few instances in which the desire to change a particular trait led to subsequent changes in other, non-corresponding traits. Specifically, relative to individuals who wanted to change any other trait, those who indicated a desire to increase levels of Extraversion increased in Agreeableness and Emotional Stability. These results are consistent with the notion that participants employ personality change strategies that may actually work to influence the development of non-targeted traits. For instance, people who wish to increase in levels of Extraversion may see this goal as a means to making more friends or being less socially anxious. As a result, they may try to increase their likability and friendliness (characteristics more associated with Agreeableness) or decrease their social anxiety and insecurities (characteristics associated with Emotional Stability). The potential ambiguity of our measure, in particular the fact that we did not ask participants why they wished to change aspects of themselves, needs to be addressed in subsequent research.

While we have attempted to explain these counter intuitive findings, these negative effects barely cross the threshold of significance and are thus particularly susceptible to Type I error. Therefore, these effects should be replicated before taken as veridical effects worthy of explanation.

\subsection{Perceptions of personality change}

While the limitations of sample size constrain our capacity to understand the full picture of how perceptions of personality change relate to actual and desired change, the aforementioned analyses provide insights in to how individuals conceptualize their volitional personality change journey. First, among the minority of participants who perceived personality change at follow-up, only those who became less emotionally stable were correct. Broadly speaking then, our data suggests that individuals are limited in their ability to correctly perceive volitional personality change. This finding is an interesting departure from previous research that has demonstrated that incoming college students accurately report their personality change four years later (Robins, Noftle, Trzesniewski, \& Roberts, 2005). College students may need more time to experience life as a college student and reflect on changes in their personalities throughout to make accurate judgements of their personality change. In other words, six months may not be enough time to become aware of changes in one's personality. Finally, despite, or perhaps because of, the absence of change, a relatively large percentage of individuals maintained their personality change desires. It is possible, therefore, that the desire to change personality is a constant, potentially ever moving target encompassing many overlapping personality processes. Over the course of 6-months and 1-year timeframes, they may not be able to hit the target, yet their inherent drive towards selfimprovement enables them to maintain these personality change goals.

\subsection{Change and college}

Any and all noted corresponding and non-corresponding desired-actual personality change relations were observed among the college students. College is a particularly transformative period in one's life and personality change may be especially important to ensure current and subsequent social, psychological, and professional success (Robins \& Roberts, 2004; Roberts, Robins, Trzesniewski, \& Caspi, 2003; Sanford, 1956). Thus, relative to other periods in the lifespan, college may be a time in which individuals are more motivated to change their personalities and may therefore, make a more consistent and concerted (albeit often misdirected) effort in achieving their personality change desires. Furthermore, for some individuals, the decision to attend college may be influenced in part by the opportunity for self-discovery or a personality transformation. This possibility should be explored in future, by studying the volitional change process among young adults who are, and are not, enrolled in college.

\subsection{Limitations on generalizability and future directions}

The current project is unique in its use of an idiographicnomothetic method to assess volitional personality change in both internet and college student populations without any intervening source. Despite this contribution, this project is not without its limitations.

First and foremost, we had significant attrition in both of our samples. Indeed, only approximately half of the Internet and college samples returned to the follow-up assessment. While we did work to account for this missingness, a synthetic sample is never as good as a complete, true sample. This issue is compounded by the fact that we only had two points of assessment. Specifically, we were limited in our ability to detect actual changes personality that were distinct from stat-level fluctuations (Fraley \& Roberts, 2005). On a conceptual level, more assessment points would help us understand more about the trajectories of volitional personality change. For instance, it may be the case that individuals with personality change goals make a lot of progress in the first four months after the conception of their goal (see Hudson \& Fraley, 2016), but then feel comfortable in their growth and stop concerted efforts towards continued change, which may cause to revert back, or even regress, in their progress. Future investigations should collect multiple waves of data. 
Next, our nomothetic-ideographic approach is limited both analytically and conceptually. First, the dichotomous nature of participants responses and subsequent coding system limits how much variability we can detect in participants volitional personality change responses. This relatively low variability, in turn, reduced the power necessary to detect potentially meaningful relationships between the desire to change one's personality and actual personality change.

On a conceptual level, while an open-ended method helps capture the most salient personality change desire, it is less sensitive with respect to the ability to distinguish the strength of these personality changes desires. In other words, participants may have other personality change desires of varying degrees that are perhaps not readily accessible to them when asked what they are currently changing about themselves. Despite these limitations, we believe a nomothetic-idiographic approach to studying volitional personality change adds to the emerging field by offering a methodological and conceptual complement to the hands-on, Likert-type, and relatively short time-frame approach to studying volitional personality change over time that currently dominates the field. It is important to note that only on rare occasion can a single methodological approach provide a complete picture of a given psychological phenomenon. We believe that the adoption of Likert-type and open-ended methods in tandem would yield an even more in-depth assessment of the volitional personality change process. Comparing results between open-ended and Likert-type methods would further our understanding of volitional personality change methods as well as highlight ways in which these methods are complementary. For example, open-ended methods may prompt participants to think about all aspects of their personalities that researchers may have overlooked, whereas Likert-type assessments of prespecified items allow for a more focused and psychometrically sound empirical enterprise (Miller et al., 2019, Hudson \& Fraley, 2015, 2016). In sum, volitional personality change is an emerging field and future work should utilize multiple assessment methods during multiple assessment time-periods in order to provide a comprehensive analysis of the boundary conditions for which volitional personality change is possible.

Next, both samples were drawn from the United States. It may be the case that there are cultural differences in the ways in which individuals approach volitional personality change. Speaking to this possibility, Robinson et al. (2015) observed that, relative to the UK and US, Iranian participants tended to have a greater prevalence for personality change goals, as measured by a Likert-type measure. Collecting cross-cultural data, however, is not without its pitfalls. In particular, Likert-type scales developed in the US often suffer from various response biases when used in crosscultural contexts (e.g., extreme responding, the reference group effect, acquiescence; Heine, Lehman, Peng, \& Greenholtz, 2002). Given these cultural differences, the use of ideographic, openended responses to assess volitional personality change may lead to a more in-depth and un-biased understanding of these cultural differences beyond US-developed Likert-scale measures (see Baranski, 2018).

Finally, individuals' volitional personality change desires may hold relevance to personality characteristics distinct from traits. McAdams (1995), for example, highlighted the importance of studying the person along three conceptual levels: traits, motivations, as assessed via measures such as personal strivings inventory (see Emmons, 1999), and narrative identity. Volitional personality change may both influence, and be informed by, constructs such as personal goals and autobiographical narratives. Just as it is true that a variety of measures should be adopted in the study of volitional personality change, so too is it true that researchers in this field should adopt a more inclusive and accommodating conception of the persons they aim to study.

\section{Conclusion}

This study explored individuals' ability to change their personalities. In all accounts, this was an investigation in situ, meaning that we assessed the volitional personality change as it occurs in the real world. Participants described their volitional personality change desires in their own words and were then left to their own devices to accomplish these desires. Our findings help illuminate the difficulty inherent in purposefully changing one's traits without help from outside sources, while also suggesting that individuals' perceptions of change, in large part, do not reflect this difficulty.

\section{Author contribution}

All authors contributed equally to study conceptualization and planning and report editing. Erica Baranski was the primary contributor to data collection and report writing, Jacob Gray was the primary contributor to data analysis, Patrick Morse was the primary contributor to data preparation and William Dunlop was the primary investigator on the project.

\section{Declaration of Competing Interest}

The author(s) declared no potential conflicts of interest with respect to the research, authorship, and/or publication of this article.

\section{Acknowledgements}

Support for the project was provided by a fellowship and startup funds provided by the University of California, Riverside given to the forth author.

\section{Appendix A. Supplementary material}

Supplementary data to this article can be found online at https://doi.org/10.1016/j.jrp.2019.103910.

\section{References}

Allemand, M., \& Flückiger, C. (2017). Changing personality traits: Some considerations from psychotherapy process-outcome research for intervention efforts on intentional personality change. Journal of Psychotherapy Integration, 27, 476-494.

Allison, P. D. (2003). Missing data techniques for structural equation modeling. Journal of Abnormal Psychology, 112, 545-557.

Baranski, E.N. (2018). Volitional personality change across 58 countries (Doctoral dissertation, UC Riverside).

Baranski, E. N., Morse, P. J., \& Dunlop, W. L. (2017). Lay conceptions of volitional personality change: From strategies pursued to stories told. Journal of Personality, 85, 285-299.

Bauer, M., Böhrer, H., Aichele, G., Bach, A., \& Martin, E. (2001). Measuring patient satisfaction with anaesthesia: Perioperative questionnaire versus standardised face-to-face interview. Acta Anaesthesiologica Scandinavica, 45, 65-72.

Biderman, M. D., Nguyen, N. T., Cunningham, C. J., \& Ghorbani, N. (2011). The ubiquity of common method variance: The case of the Big Five. Journal of Research in Personality, 45, 417-429.

Boyatzis, R., \& McKee, A. (2006). Intentional change. Journal of Organizational Excellence, 25, 49-60.

Boyatzis, R. E. (2006). An overview of intentional change from a complexity perspective. Journal of Management Development, 25, 607-623.

Boyatzis, R. E., \& Akrivou, K. (2006). The ideal self as the driver of intentional change. Journal of Management Development, 25, 624-642.

Buhrmester, M., Kwang, T., \& Gosling, S. D. (2011). Amazon's Mechanical Turk a new source of inexpensive, yet high-quality, data? Perspectives on Psychological Science, 6, 3-5. 
Chiu, C. Y., Hong, Y. Y., \& Dweck, C. S. (1997). Lay dispositionism and implicit theories of personality. Journal of Personality and Social Psychology, 73, 19-30.

Emmons, R. A. (1999). The psychology of ultimate concerns: Motivation and spirituality in personality. Guilford Press.

Enders, C. K. (2017). Multiple imputation as a flexible tool for missing data handling in clinical research. Behaviour Research and Therapy, 98, 4-18.

Enders, C. K., \& Bandalos, D. L. (2001). The relative performance of full information maximum likelihood estimation for missing data in structural equation models. Structural Equation Modeling, 8, 430-457.

Frisch, M. B. (2013). Evidence-based well-being/positive psychology assessment and intervention with quality of life therapy and coaching and the Quality of Life Inventory (QOLI). Social Indicators Research, 114, 193-227.

Fraley, R. C., \& Roberts, B. W. (2005). Patterns of continuity: a dynamic model for conceptualizing the stability of individual differences in psychological constructs across the life course. Psychological Review, 112, 60-74.

Funder, D. C., \& Ozer, D. J. (1983). Behavior as a function of the situation. Journal of Personality and Social Psychology, 44, 107-112.

Geer, J. G. (1991). Do open-ended questions measure "salient" issues? Public Opinion Ouarterly, 55, 360-370.

Graham, J. W. (2009). Missing data analysis: Making it work in the real world. Annual Review of Psychology, 60, 549-576.

Grimm, K. J., An, Y., McArdle, J. J., Zonderman, A. B., \& Resnick, S. M. (2012). Recent changes leading to subsequent changes: Extensions of multivariate latent difference score models. Structural Equation Modeling: A Multidisciplinary Journal, 19, 268-292.

Heine, S. J., Lehman, D. R., Peng, K., \& Greenholtz, J. (2002). What's wrong with crosscultural comparisons of subjective Likert scales?: The reference-group effect. Journal of Personality and Social Psychology, 82, 903-918.

Hogan, R., \& Roberts, B. W. (2004). A socioanalytic model of maturity. Journal of Career Assessment, 12, 207-217.

Hudson, N. W., \& Fraley, R. C. (2015). Volitional personality trait change: Can people choose to change their personality traits? Journal of Personality and Social Psychology, 109, 490-507.

Hudson, N. W., \& Roberts, B. W. (2014). Goals to change personality traits: Concurrent links between personality traits, daily behavior, and goals to change oneself. Journal of Research in Personality, 53, 68-83.

John, O. P., Naumann, L. P., \& Soto, C. J. (2008). Paradigm shift to the integrative Big Five trait taxonomy. Handbook of Personality: Theory and Research, 3, 114-158.

John, O. P., \& Srivastava, S. (1999). The Big Five trait taxonomy: History measurement, and theoretical perspectives. Handbook of Personality: Theory and Research, 2, 102-138.

Kaiser, R. T., \& Ozer, D. J. (1997). Emotional stability and goal-related stress. Personality and Individual Differences, 22, 371-379.

Little, B. R. (1983). Personal projects: A rationale and method for investigation. Environment and Behavior, 15, 273-309.

Martin, L. S., Oades, L. G., \& Caputi, P. (2014). Intentional personality change coaching: A randomised controlled trial of participant selected personality facet change using the Five-Factor Model of personality. International Coaching Psychology Review, 9, 196-209.

Martin, L. S., Oades, L. G., \& Caputi, P. (2012). What is personality change coaching and why is it important?. International Coaching Psychology Review, 7, 185-193.

McAdams, D. P. (1995). What do we know when we know a person?. Journal of Personality, 63, 365-396.
McArdle, J. J., \& Hamagami, F. (2001). Latent difference score structural models for linear dynamic analyses with incomplete longitudinal data. In Linda M. Collins \& Aline G. Sayer (Eds.), New methods for the analysis of change (pp. 139-175). Washington, DC, US: American Psychological Association. xxiv, 442 pp.

McCredie, H. (2013). What is personality change coaching and why is it important? A response to Martin, Oades \& Caputi. International Coaching Psychology Review, $8,101-103$.

Miller, T. J., Baranski, E. N., Dunlop, W. L., \& Ozer, D. J. (2019). Striving for change: The prevalence and correlates of personality change goals. Journal of Research in Personality, 80, 10-16.

Olson, J., \& Muderrisoglu, A. (1979). The stability of responses obtained by free elicitation: implications for measuring attribute salience and memory structure. In William L. Wilkie (Ed.). NA - advances in consumer research (Vol. 06, pp. 269-275). Ann Abor, MI: Association for Consumer Research.

Quintus, M., Egloff, B., \& Wrzus, C. (2017). Predictors of volitional personality change in younger and older adults: Response surface analyses signify the complementary perspectives of the self and knowledgeable others. Journal of Research in Personality, 70, 214-228.

Roberts, B. W., \& Mroczek, D. (2008). Personality trait change in adulthood. Current Directions in Psychological Science, 17, 31-35.

Roberts, B. W., \& Robins, R. W. (2004). Person-Environment fit and its implications for personality development: A longitudinal study. Journal of Personality, 72, 89-110.

Roberts, B. W., Robins, R. W., Trzesniewski, K. H., \& Caspi, A. (2003). Personality trait development in adulthood. Handbook of the Life Course, 579-595.

Roberts, B. W., Walton, K. E., \& Viechtbauer, W. (2006). Patterns of mean-level change in personality traits across the life course: A meta-analysis of longitudinal studies. Psychological Bulletin, 132, 1-25.

Roberts, B. W., Luo, J., Briley, D. A., Chow, P. I., Su, R., \& Hill, P. L. (2017). A systematic review of personality trait change through intervention. Psychological Bulletin, $143,117$.

Robins, R. W., Fraley, R. C., Roberts, B. W., \& Trzesniewski, K. H. (2001). A longitudinal study of personality change in young adulthood. Journal of Personality, 69, 617-640.

Robins, R. W., Noftle, E. E., Trzesniewski, K. H., \& Roberts, B. W. (2005). Do people know how their personality has changed? Correlates of perceived and actual personality change in young adulthood. Journal of Personality, 73, 489-522.

Robinson, O. C., Noftle, E. E., Guo, J., Asadi, S., \& Zhang, X. (2015). Goals and plans for Big Five personality trait change in young adults. Journal of Research in Personality, 59, 31-43.

Sanford, N. (1956). Personality development during the college years. Journal of Counseling E Development, 35, 74-80.

Soto, C. J., \& John, O. P. (2017). The next Big Five Inventory (BFI-2): Developing and assessing a hierarchical model with 15 facets to enhance bandwidth, fidelity, and predictive power. Journal of Personality and Social Psychology, 113, 117-143.

Spence, G. B., \& Grant, A. M. (2005). Individual and group life coaching: Initial findings from a randomised, controlled trial. Evidence-Based Coaching Volume 1: Theory, Research and Practice from the Behavioural Sciences, 143-158.

Srivastava, S., John, O. P., Gosling, S. D., \& Potter, J. (2003). Development of personality in early and middle adulthood: Set like plaster or persistent change? Journal of Personality and Social Psychology, 84, 1041-1053.

Young, R. A., Valach, L., \& Domene, J. F. (2005). The action-project method in counseling psychology. Journal of Counseling Psychology, 52, 215-223. 